\title{
Creatividad y daño cerebral adquirido por ictus
}

\section{Creativity and brain damage acquired by stroke}

Rebeca Zurru Fernández ${ }^{1}$

\section{Resumen}

Esta investigación pretende conocer desde un estudio de casos múltiple, en qué medida la implementación de talleres dedicados a estimular la creatividad de personas con daño cerebral adquirido por accidentes cerebro vasculares (ACV], puede enriquecer la operatividad de otras terapias llevadas a cabo paralelamente, durante el proceso de rehabilitación de los mismos. Pretendiendo cuantificar hasta qué punto la práctica creativa puede configurarse como estrategia dedicada a educar la percepción, expresión, memoria y proyección de pacientes con daño cerebral adquirido [DCA], desde una perspectiva artístico- terapéutica para la salud mental, aspiramos a fomentar la autonomía e integración social de este colectivo.

Palabras clave: Arte, Salud, Creatividad, Operatividad, Neuro-rehabilitación, Accidente Cerebrovascular

\section{Abstract}

This research is based on a multiple case study and shows to what extent the implementation of workshops, stimulating the creativity of people with brain damage of strokes, can enrich the operation of other therapies, carry out parallel during the process of rehabilitation. The research aims to quantify the extent to which creative practice can be configured as a strategy dedicated to educating the perception, memory and projection of patients with traumatic brain injury [TBl], from an artistic therapeutic perspective from mental health, the promotion of the autonomy and the social integration of these patients is aspired.

Keywords: Art, Health, Creativity, Operativity, Neuro-rehabilitation, Stroke.

"No se puede refrenar o neutralizar un afecto excepto por un afecto contrario que sea más fuerte que el afecto que se quiere refrenar"

Antonio Damasio "En busca de Spinoza”

\footnotetext{
${ }^{1}$ Universitat Politècnica de València. zurrurebeca@gmail.com

Artículo recibido: 11 de mayo de 2017; aceptado: 22 de junio de 2017.
} 


\section{Introducción}

Teniendo en cuenta las últimas estadísticas presentadas por el Plan de Atención al lctus en la Comunidad Valenciana [2010-2015] y las cifras destacadas por la Federación Española de Daño Cerebral [FEDACE], hoy en día podemos clasificar el lctus, siendo la tercera causa de muerte en España, como la principal enfermedad neurológica que causa discapacidad parcial y total en un 89 \% de los adultos que la sufren. En nuestro país, las cifras se elevan a unas 327.650 personas con este tipo de Daño Cerebral Adquirido [DCA]. Uno de cada cuatro somos menores de 50 años.

La educación e implicación comunitaria, concienciación social y prevención sobre estos hechos, han permitido que durante las últimas décadas, las estadísticas obtenidas sobre la morbimortalidad causada por Accidentes Cerebrovasculares [ACV], haya reducido de modo notable. Esto nos presenta una nueva realidad donde el DCA durante la fase aguda de sus supervivientes, se convierte en problema de primer orden que causa dependencia e invalidez permanente en nuestra sociedad. Para esta urgente necesidad, Valencia ofrece casi una decena de Centros, Hospitales e Institutos dedicados a la neurorehabilitación de pacientes agudos y crónicos que hayan sufrido este tipo de trauma.

\section{El daño adquirido por ictus}

Creyendo saber quiénes somos y cómo funciona nuestro cuerpo, meditemos sobre las partes que componen su identidad. Qué nos define como individuos o qué rasgos nos caracterizan como tales. Deconstruyamos la idea creada en torno a nuestro yo más íntimo. $A$ Ella por ejemplo, balanceada entre valores, siempre le caracterizaron sus manos; la sutileza y refinada desenvoltura que la dominaba ante cualquier situación.

Las secuelas de un lctus pueden provocar la pérdida de capacidades físicas y mentales que diariamente damos por hecho. Sonreír, hablar, sentir tristeza o vergüenza, entre otras.

Tras el golpe ${ }^{3^{3}}$, repentinamente parece olvidarse el registro de experiencias de nuestra memoria biográfica. Ajenos a lo que fuimos, en ocasiones debemos aprender a ser ciegos o ver cómo nuestro cuerpo al que creíamos estar entrelazados de forma inconsutil, se torna carga cotidiana. Determinados por el funcionamiento de sistemas cerebrales, como afirmaría Damasio [2005], cambian los principios y comportamientos éticos de líderes apreciados por sus comunidades. El gobierno de nuestra vida, contratos sociales y afectivos desaparecen, de manera que sentir, finalmente no resulta ser un proceso pasivo.

\footnotetext{
${ }^{2}$ Primer estudio de caso realizado en el Hospital Doctor Moliner con una paciente de mediana edad en periodo de rehabilitación tras sufrir un Ictus Isquémico en Noviembre de 2015.

${ }^{3}$ La traducción latina de ictus significa golpe. Participio pasado de ic\re[golpear, asestar un golpe con violencia].
} 


\section{Vínculos entre creatividad, salud y ACV}

Ya desde neonatos aprendemos sobre una serie de acontecimientos que educan los sentimientos de dolor y placer para sobrevivir con bienestar en el medio. La habilidad de la mente para crear como mecanismo de supervivencia, en su base depende de una serie de relaciones objetuales o lazos creados con nuestro entorno. El crecimiento plagado de dolores, bajo un alto nivel de ansiedades desde el momento del parto, incentiva la capacidad de la mente para reponerse y encontrar bajo la mano de su creatividad nuevas vías. El despegue del objeto amado, "del vientre a la fría camilla", como apuntó Cardenal [2017] durante la Jornada del Instituto de Estudios Psicosomáticos $^{4}$ en Valencia, por norma general supone la primera crisis humana. En este momento debemos separarnos de lo que en principio era parte íntegra de nuestra identidad en el espacio.

La madre como foco de interés por su belleza y base de conocimiento súbitamente despierta la curiosidad del neonato, quien en ella encuentra sus primeros nexos con el medio, el yo materno, completa al yo infantil durante el embarazo y su periodo de lactancia. El pecho como continuidad e integración con la madre, se muda pretexto para forjar la base creativa de nuestra mente. Tomando intuitivamente su ejemplo, al liberarnos de esta fantasía, abrimos nuestra independencia mental. Al reconocer nuestro yo separado de la misma, nuestra creatividad comienza a buscar nuevas relaciones amorosas que nos alejan o acercan de lo que reconocemos como sentimientos de dolor y placer.

En esta fase del crecimiento y desarrollo individual, podemos encontrar paralelismos con el trauma inscrito en el DCA por lctus. Atrapados en relaciones establecidas con el entorno y con uno mismo, nuevamente se plantea el desgarre de objetos amorosos. Hablamos de ingredientes tan íntimos como la aceptación de separación u olvido de nuestra propia identidad. Sometidos a la descontextualización del cuerpo en un $45 \%$ de los casos, la famosa independencia se ahoga en su propia falta de sentido. De nuevo nos vemos ante una situación donde capacidades como la creatividad, deben desvelar nuevas oportunidades que impliquen la integración desde el medio para el entorno.

\section{Objetivos}

La Organización mundial de la Salud [OMS, 2013] define la Salud Mental como un estado de bienestar en el que el individuo es lúcido de sus propias capacidades, afronta las tensiones cotidianas de la vida, trabaja de manera productiva y es capaz de contribuir con su comunidad.

Procurando respuestas capaces de abordar estas cuestiones, las distintas Unidades de Daño Cerebral de nuestra ciudad, ponen de manifiesto una serie de programas neurorehabilitadores

${ }^{4}$ En la Jornada del Instituto de Estudios Psicosomáticos sobre "Las capacidades de la mente para crear y pensar" (2017), Cardenal habló del Método de Observación de lactantes creado por Esther Bick [1964]. 
dedicados al manejo de alteraciones conducto-emocionales, recuperación de déficit cognitivos puntuales y a la puesta en práctica de actividades para retomar ocupaciones básicas del día a día de sus pacientes. Indispensables para el bienestar, compromiso y participación de los mismos, se abordan tratamientos como Terapia Ocupacional, Neuropsicología, Psicoterapia, Logopedia y otras actividades relacionadas con la Psiquiatría. En dicha programación regularizada, disciplinas como la Arteterapia proyectadas a los mismos enunciados, no se incluyen de manera regularizada.

Demostrados los beneficios que disciplinas como ésta proporcionan a la sociedad, desde nuestra área de trabajo confiamos en los múltiples resultados que muestran diversos estudios empíricos y desarrollos teóricos sobre la necesidad del arte en diferentes contextos sociales como éste.

El concepto de arte como terapia tomó forma en la segunda mitad del S. XX como herramienta dirigida para la rehabilitación de personas con discapacidades emocionales y cognitivas. Desde las últimas décadas del S. XIX, ya pudimos ver cómo fue utilizada por psiquiatras europeos ${ }^{5}$ dedicados a estudiar las obras de arte de individuos con alteraciones mentales. Más tarde, otras áreas de conocimiento como la educativa y la social, se vieron involucradas en una misma búsqueda de posibilidades de entre las causas y efectos que este tipo de disciplinas podían ofrecer. Conformes con esta idea, Araujo y Gabelán [2010] entre otros, mantuvieron que la Arteterapia principalmente estaba influenciada por tres campos de conocimiento: el artístico, el educativo y el de la salud.

Procurando respuestas capaces de devolver la independencia de este colectivo, desde nuestro marco decidimos cuantificar en qué medida, la implementación de programas educativos desde una perspectiva artístico-terapéutica dedicados a estimular la creatividad, pueden contribuir al incremento cualitativo de conocimientos que enriquezcan la operatividad y permitan el máximo rendimiento de procesos asistenciales dirigidos para la inclusión y autonomía de pacientes afectados crónicamente por esta enfermedad. Procuramos conocer hasta qué punto podemos vincular creatividad y salud mental de personas con DCA por lctus. Adaptar nuestra área de conocimiento a los diferentes requisitos presentados por esta comunidad. Para ello, estudiamos en qué medida la creatividad y sus diferentes manifestaciones son necesarias para una supervivencia digna bajo cualquier circunstancia.

\section{Metodología}

Alejados de la idea de que las rutas neurales ${ }^{6}$ tengan una única dirección, en este nuevo capítulo de relaciones amorosas, desde un marco conceptual abierto e interactivo desarrollado por metodologías de investigación cualitativas, el proyecto se basa en un estudio de casos múltiple

\footnotetext{
${ }^{5}$ Con intención de estudiar el valor estético y las capacidades terapéuticas de la ocupación creativa, entre 1890 y 1920 , el alemán Prinzhom (1890) agrupó una colección de más de cinco mil obras creadas por enfermos mentales.

6 Antonio Damasio cartografía la geografía del cerebro. En busca de Spinoza [2005) nos presenta mapas cerebrales correspondientes a estados corporales encargados de crear lo que reconocemos como sentimientos.
} 
que pretende cuantificar sobre técnicas estadísticas los datos obtenidos de pacientes y del equipo de trabajo de distintas entidades colaboradoras en las que desarrollemos la investigación.

De naturaleza empírica, tomamos la práctica creativa como puente para la recogida de datos y notas de campo que permitan verificar o refutar las hipótesis señaladas como punto de partida. Cual investigación básico-aplicada, desde la observación participativa, como modeladores intervenimos desde un contacto directo y cercano a los participantes. Procuramos crear un clima constructivo y de confianza, un ambiente cómodo y libre de ataduras o prejuicios que permita realizar las distintas actividades, talleres, puestas en común y debates propuestos durante la programación señalada.

\section{Estudios de caso}

La primera hipótesis sobre cómo el diseño e implementación de programas artísticos puede contribuir al bienestar emocional de pacientes con daño cerebral durante el periodo de su rehabilitación, surgió tras realizar durante un periodo de tres meses en el Hospital Doctor Moliner [Bétera, 2015], un estudio de caso con una paciente de mediana edad que había sufrido un lctus Isquémico.
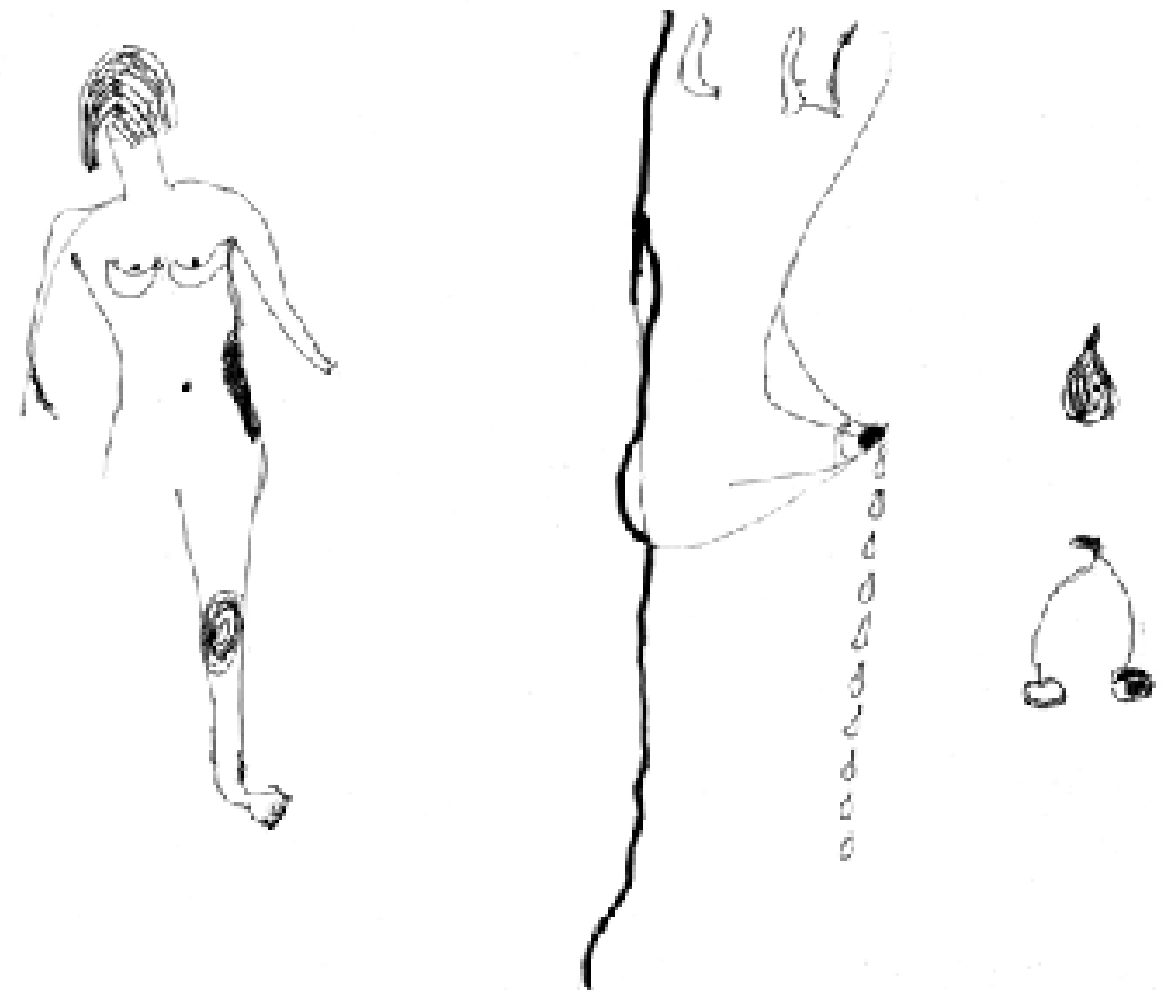

Figura 1 (2015). Práctica creativa libre por una paciente en periodo de rehabilitación ingresada en el Hospital Doctor Moliner, Bétera. 
Durante la fase subaguda de su rehabilitación, normalmente en pacientes graves oscila entre cinco y ocho meses, fuimos diariamente partícipes de cómo en una situación de búsqueda identitaria continua, la práctica artística libre podía contribuir a establecer relaciones directas consigo misma y con su entorno.

En busca de calma y asentamiento de emociones, durante las sesiones la paciente parecía encontrar reposo liberándose del continuo zig-zag personal, en el que tres meses atrás despertó bajo una hemiparesia izquierda y carente de algunos sentimientos como la tristeza o la propia inhibición.

Documentados por su biografía y por sus trabajos artísticos producidos previamente al ACV, pudimos emplear los resultados obtenidos durante las noventa sesiones realizadas, para objetivizar las notas argumentadas en líneas anteriores.
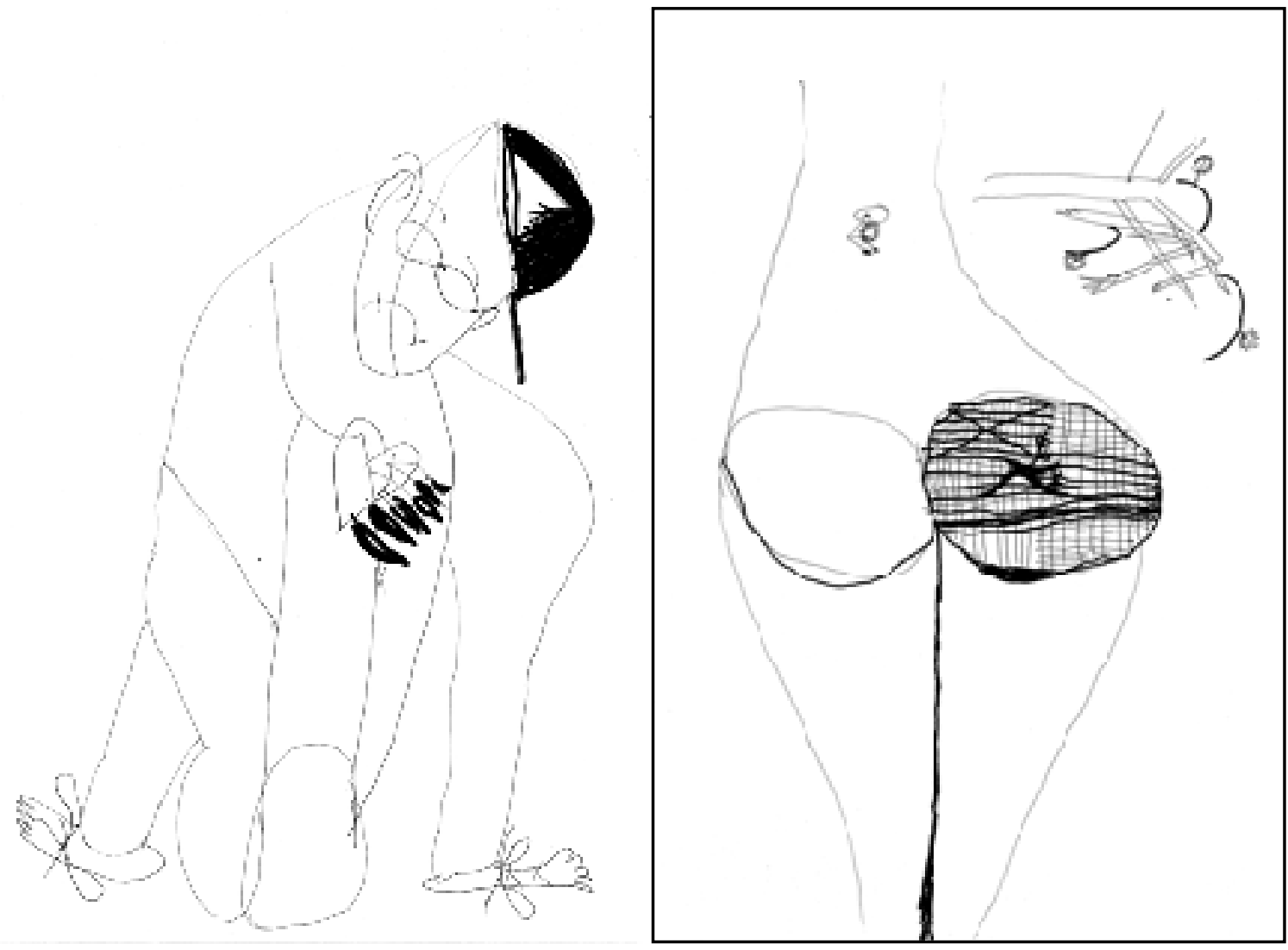

Figura 2 (2015). Práctica creativa libre por una paciente en periodo de rehabilitación ingresada en el Hospital Doctor Moliner, Bétera.

Figura 3 (2015). Práctica creativa libre por una paciente en periodo de rehabilitación ingresada en el Hospital Doctor Moliner, Bétera. 
Los frutos obtenidos durante esta práctica, abrieron nuevas hipótesis donde la toma del Arte no sólo serviría como vía de expresión, comunicación, conocimiento y disfrute, sino también como terapia para educar una creatividad dirigida a la operatividad diaria de personas que hayan sufrido daños cerebrales agudos.

Continuamos el estudio en la Unidad de Daño Cerebral Hermanas Hospitalarias [Valencia, 2016]. Durante un periodo de cinco meses abordamos una serie de talleres adecuados a las necesidades presentadas por los pacientes. Desde una postura activa entre estudiosos y estudiados, la voz de los mismos, como resultado de las prácticas creativas, cuestionarios y ritmo del grupo, cobró todo el protagonismo para el análisis de datos que posteriormente cuantificaría los resultados.

Basados en la individualidad de nueve pacientes, procuramos que el diagnóstico inicial dejara de ser una etiqueta para convertirse en descripción tanto de los puntos fuertes como de los débiles que presentaban a nivel cognitivo, emocional, motor y de independencia. Fue interesante notar que pese a la diversidad de oficios previos al ACV, su relación o no con la práctica artística, no se tuviera que limitar la dificultad de los enunciados propuestos.

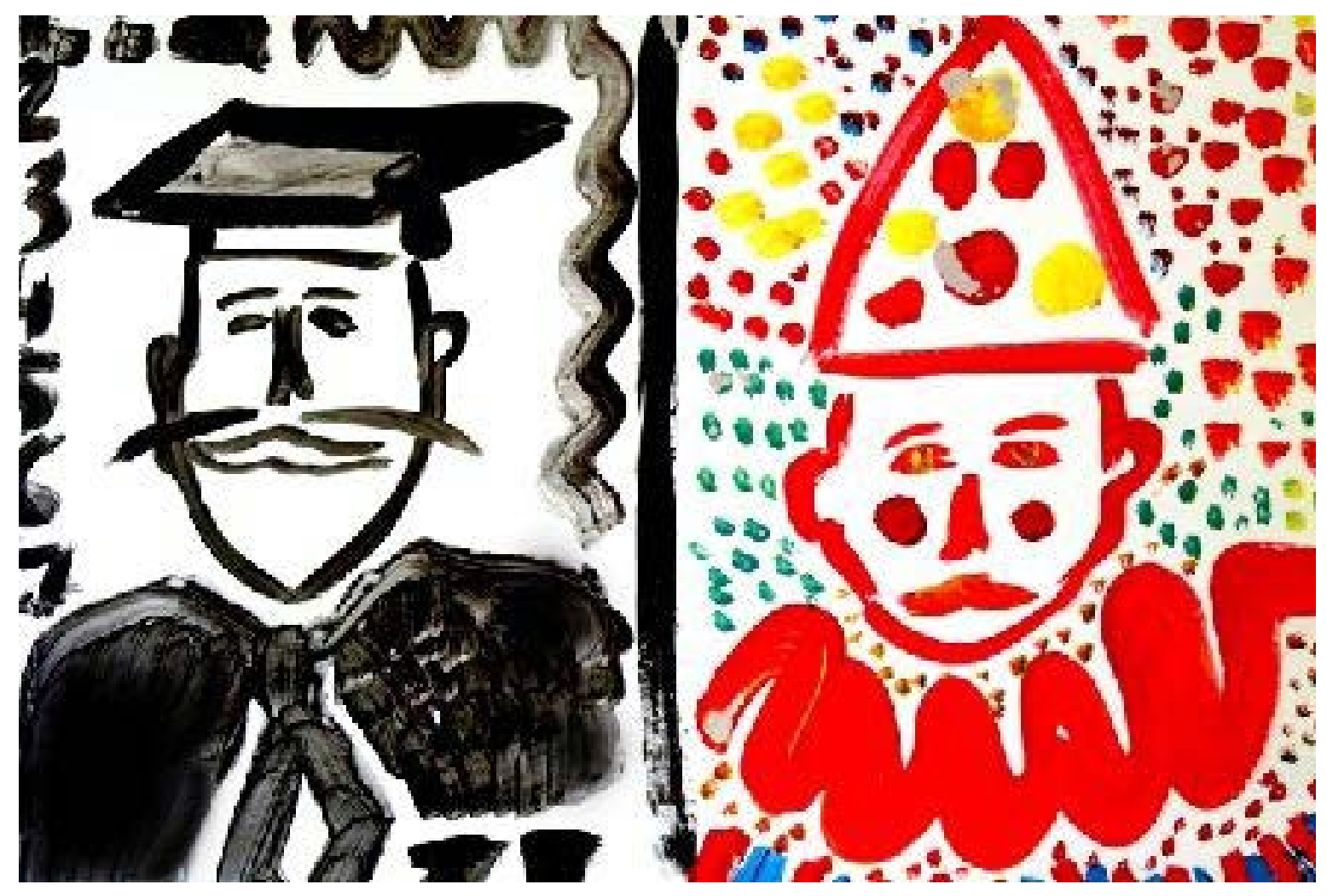

Figura 4 (2016). Autorretrato doble. Antes y después (tercer bloque, Memoria) por un paciente de la UDC Hermanas Hospitalarias, Valencia. 
Algunos ejemplos de los casos con los que tomamos contacto fueron los siguientes: Participó en nuestra investigación una mujer de 55 años que durante los últimos quince había sido ama de casa. Vinculada a algunas ocupaciones como la pintura, el collage y la jardinería en su tiempo libre, tras haber sufrido en 2015 un Ictus Isquémico de la ACM derecha y superar la fase aguda y subaguda de su rehabilitación, se le diagnosticaron distintos déficit como la pérdida de memoria a corto plazo, la atención selectiva, limitaciones en la velocidad de procesamiento y respuestas impulsivas. En dicho diagnóstico también se subrayaron dificultades en la planificación y flexibilidad en la resolución de situaciones tanto novedosas como cotidianas. La falta de conciencia del déficit dificultó su rehabilitación envolviéndola en un continuo estado de apatía y cansancio. Dependiente de terceros, el lctus además provocó que sufriera una hemiparesia izquierda de predominio braquial que le imposibilitaba llevar a cabo con normalidad un $80 \%$ de sus actividades cotidianas.

Otra de las lesiones, fue el caso de un hombre de 52 años que durante más de veinte años se había dedicado a la Informática. Tras sufrir una Embolia en 2014, provocada por un aneurisma, el paciente sumergido en una falta de iniciativa constante, no era capaz de anticipar las consecuencias que despertaban sus propios comportamientos. Como en el caso anterior, también presentaba dificultades al entablar nuevos repertorios conductuales y limitaciones al desempeñar determinadas actividades o realizar tareas que exigieran flexibilidad cognitiva, por ejemplo en el área del cálculo básico.

Otro componente del grupo fue un participante de 70 años dedicado desde hacía casi diez años a actividades artísticas como la crítica libre de arte. En 2013 sufrió un Ictus Isquémico de etiología indeterminada, esto repercutió de manera grave no sólo a sus conductas de riesgo o en su diagnóstico comunicativo: afasia motora, parafasias fonéticas y fluidez verbal disminuida gravemente, sino que también afectó otros niveles cognitivos que reflejaban impulsividad, falta de flexibilidad conductual y lentitud en el procesamiento de información. Nuevamente a nivel motor se presentaba una hemiparesia derecha, con movimientos de apertura de mano muy limitados para el desarrollo de actividades que implicaran precisión.

Sumado al grupo fue el caso de otro caballero de 62 años que sufrió un Ictus Isquémico por la obstrucción de la carótida izquierda en Septiembre de 2015. Había trabajado toda su vida en la Aeronáuticatica del puerto de Valencia y durante sus ratos libres como nos comentaron sus familiares, se dedicaba al diseño y manufacturación de minuciosas maquetas y dibujos técnicos. Aparte de una hemiparesia derecha, dependiente total de terceras personas para desempeñar un 90\% de actividad rutinarias, el golpe afectó a su comunicación a través de una afasia global. No sabía leer ni tampoco escribir y su nivel de comprensión y expresión previo a la práctica creativa parecía ser mínimo. 
Como podemos notar, este tipo de enfermedad de mil caras afecta a cada individuo de una manera única y diferente. Los cambios no se limitan a lecturas superficiales que obviamente denotan las complicaciones que puedan acarrear sus diferentes lesiones. Buscando ampliar nuestra perspectiva, para lograr una lectura real de cuáles eran las circunstancias que provocaban su frustración y sufrimiento, reflexionando globalmente sin perder la individualidad, pudimos agrupar un conjunto de déficit que tomaríamos posteriormente como punto de partida para el desarrollo de las distintas prácticas propuestas y nuevas visiones de recuperación.

Como sugirió Damasio [2005], procuramos encontrar "estímulos emocionalmente competentes que pudieran penetrar a través de la barrera de su ceguera". Para ello, pusimos en juego un conjunto de funciones de la mente que guían gran parte del pensamiento creativo y dividirían la rúbrica del programa en cuatro bloques diferenciados que darían forma a la acción participativa; la percepción, la expresión, la memoria y la proyección.

Desde el comienzo del programa pretendimos reafirmar por medio de la creatividad el punto de vista de cada participante. Ayudar a que su mirada reconociera y diera un sentido personal a los diferentes estímulos presentados. Decidimos poner a disposición una serie de lenguajes como la abstracción, capaces de subrayar la inexactitud que existe entre sujeto y objeto dentro del campo perceptivo que continuamente se ve afectado por sistemas basados en el orden. Establecer vínculos personales y educar cuan amplia es la diversidad de lecturas que tiene una misma realidad. Ganar confianza en sí mismos y motivarles a través de su propio discurso estimulando capacidades individuales como la acción creativa, necesaria para recibir, elaborar y producir respuestas efectivas ante la información presentada desde una postura subjetiva.

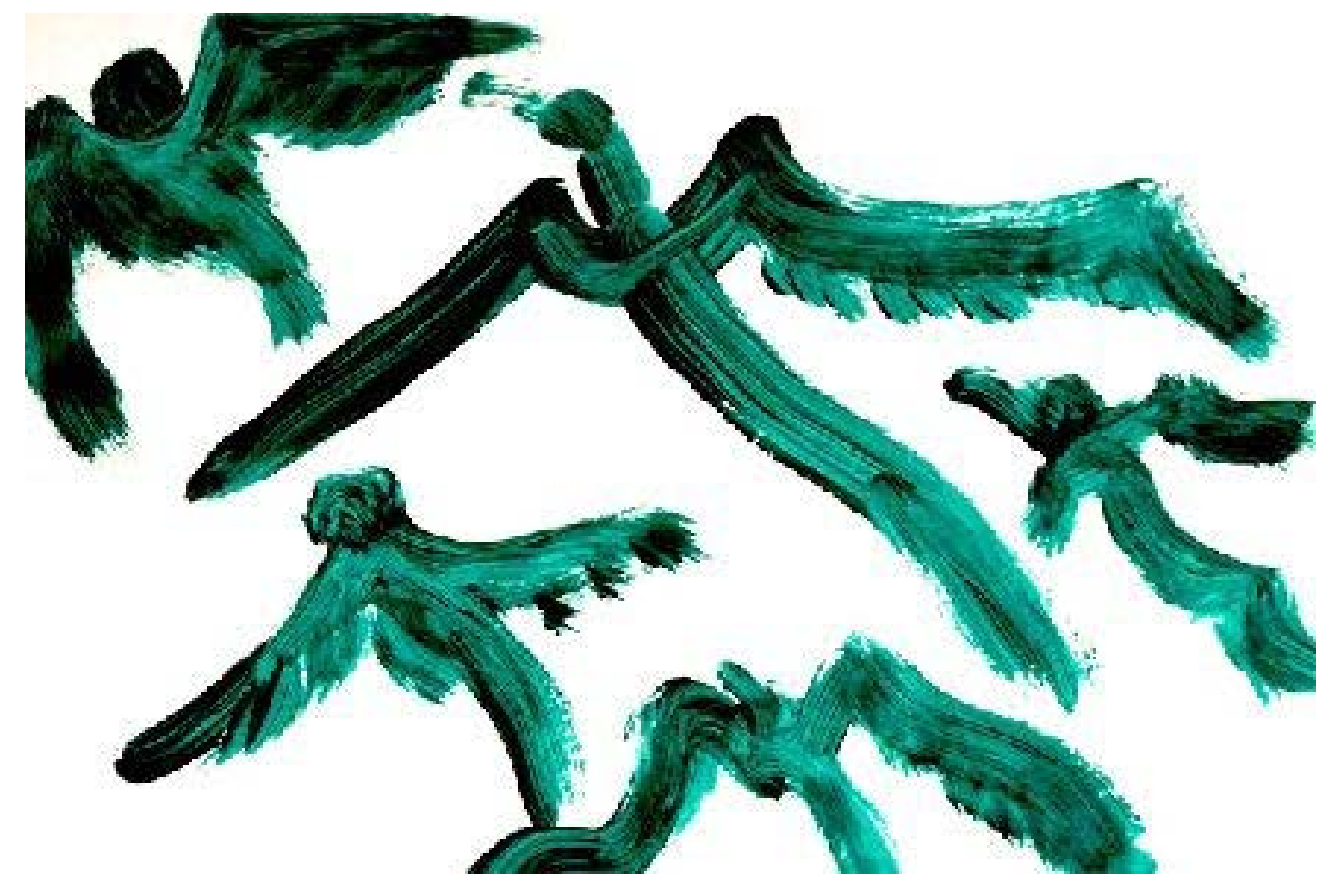

Figura 5 (2016). Interpretación de bodegón (primer bloque, Percepción) por un paciente de la UDC Hermanas Hospitalarias, Valencia. 
Dedicados a estimular la autoconfianza de los pacientes a través de su propia percepción sobre los estímulos facilitados para las distintas actividades, desde el primer bloque, conseguimos despertar la necesidad de indagar sobre sus gustos y que comenzaran a creer en la validez y fuerza de sus opiniones. Bajo dos subtítulos: la imagen y el sonido, llevamos a cabo una serie de sesiones dedicadas a distintos referentes imaginarios, visuales y auditivos, que deberían ser interpretados bajo el empleo de elementos compositivos como el color, la forma, la mancha y la línea.

La seriedad e implicación de los participantes permitió no regatear sobre la dificultad de las prácticas propuestas. Encargados de poner todos sus sentidos en juego, vista, oído, gusto y tacto, deberían construir sus propios escenarios sobre los distintos soportes facilitados y durante las puestas en común con el resto de compañeros. De nuevo se subrayaba la cantidad de alternativas diferentes que una misma realidad podía ofrecer dependiendo del receptor que se encargara de filtrarla.
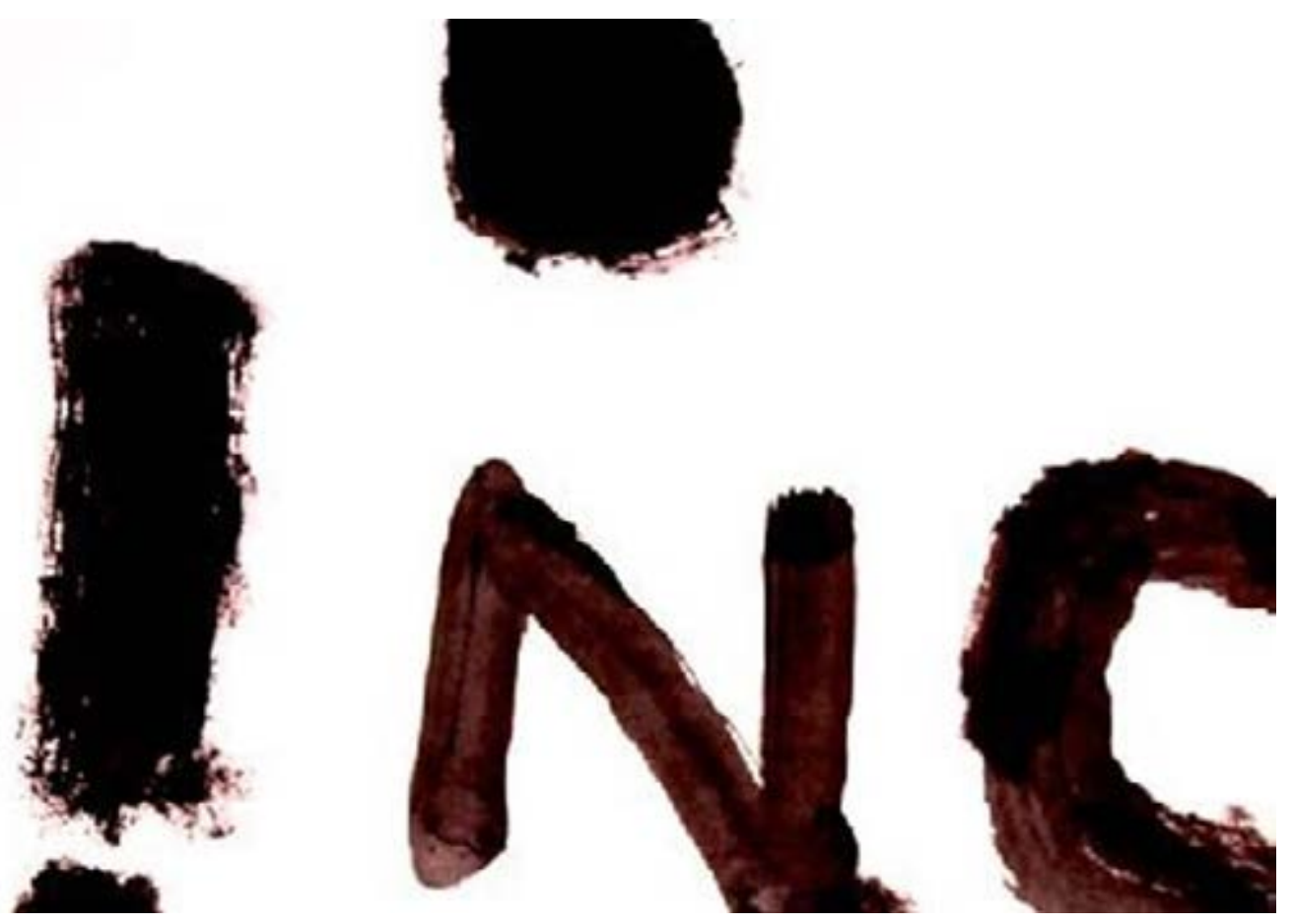

Figura 6 (2016). Interpretación de una melodía a través del empleo de la línea (primer bloque, Percepción) por un paciente con afasia global de la UDC Hermanas Hospitalarias, Valencia.

Seis sesiones posteriores, cada vez más alejado de sentidos unívocos, comenzamos a focalizar nuestra atención en otras capacidades como la expresión. Introduciendo nuevos filtros como el lenguaje y la escritura, a un nivel más complejo continuamos planteando la búsqueda de significados personales a través de los elementos compositivos que habíamos trabajado hasta la fecha. 
Con intención de empoderar a los pacientes, en esta ocasión trabajamos las ideas creadas en torno a una lista de conceptos que servían para crear un clima de complicidad que nos permitiera acercarnos a capítulos destacables de su vida. Comprender sus historias respetando la interpretación y diferencias que cada individuo otorgaba a su realidad. Por medio de lenguajes como la abstracción y figuración, representamos conceptos tales como Dependencia $e$ Independencia, por ejemplo.

Por su parte, durante el bloque de la memoria continuaron ocupando su lugar las puestas en común. Las imágenes creadas servían como pretexto para hacer lectura de los propios textos e interpretaciones personales sobre las posibles coincidencias y discrepancias que debatiríamos con pretensión a construir y educar pensamientos productivos capaces de provocar posibilidades.

En este mes y medio, utilizando diversos juegos que facilitaran lluvia de datos para establecer combinaciones nuevas, dirigimos un conjunto de propuestas para poner en estado consciente información poseída. La mayoría de los enunciados se basaron en reunir elementos aparentemente no relacionados entre sí, que fueran capaces de combinarse entre ellos para gestar una serie de narraciones pictóricas, autobiográficas o no, que comentaríamos al concluir las sesiones. Quisimos que los pacientes utilizaran la realidad como puerta de acceso a su banco de datos y ejercitaran su atención interpretando estímulos mediante esquemas conocidos que despertarían nuevos y antiguos nexos con su entorno.

A medida que nuestras mediaciones durante las actividades iban disminuyendo, decidimos introducir una última unidad que agruparía todos los contenidos abordados hasta la fecha y cerraría nuestra intervención con el grupo.

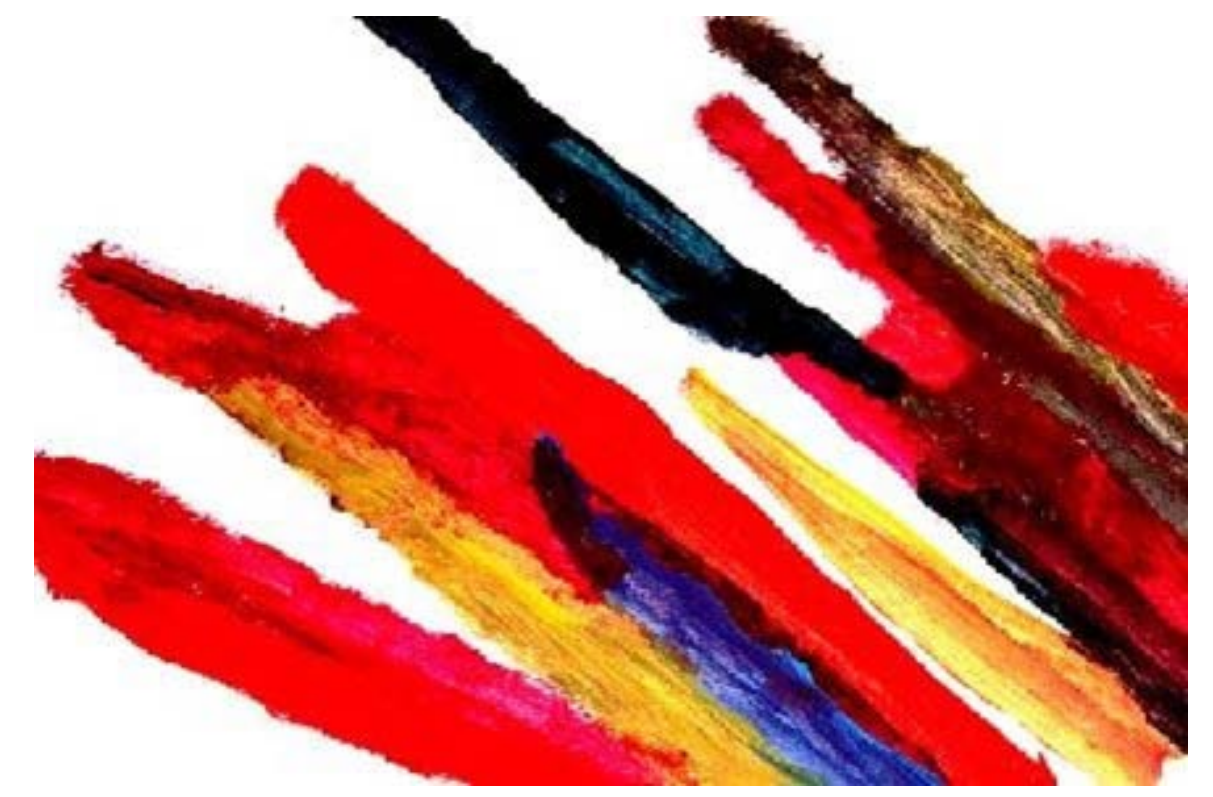

Figura 7 (2016). Interpretación del concepto Independencia (segundo bloque, Expresión) por un paciente de la UDC Hermanas Hospitalarias, Valencia. 


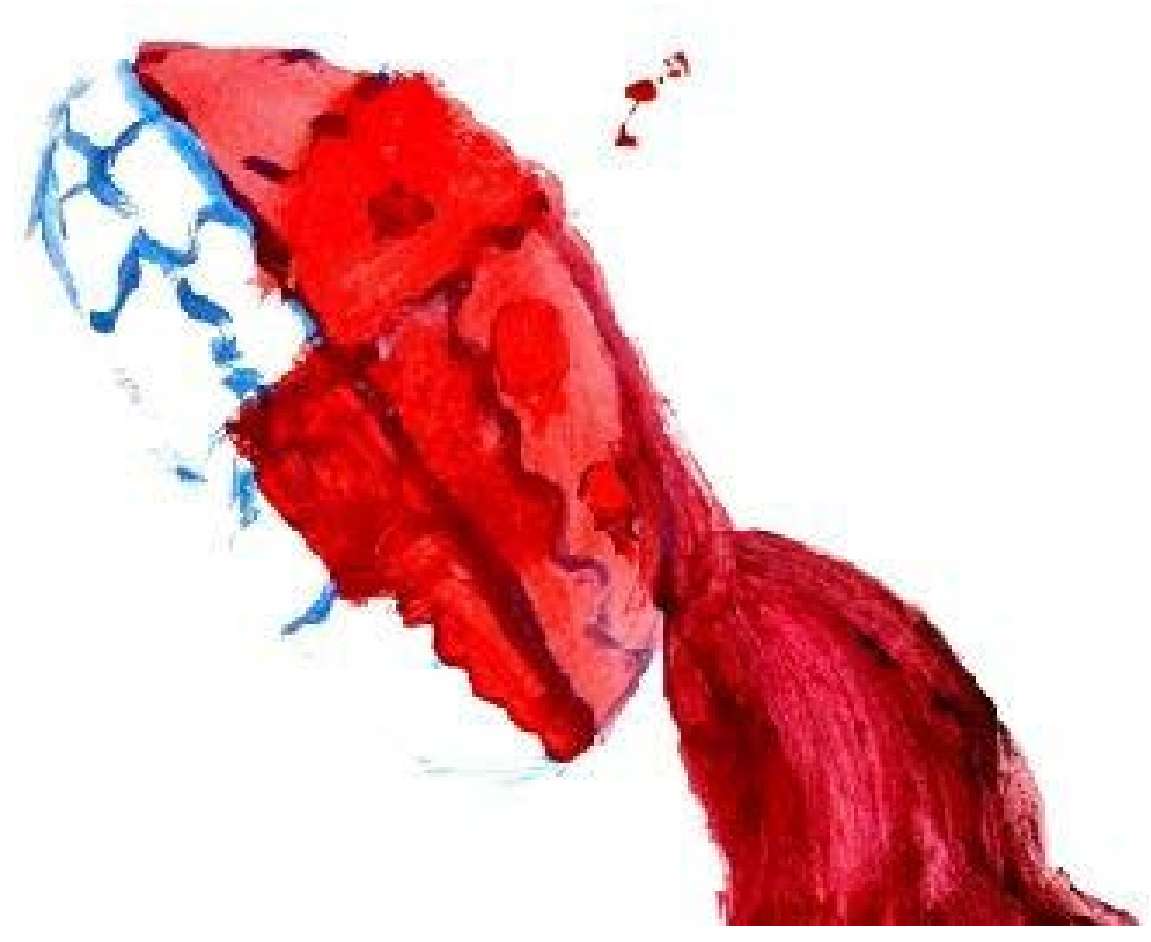

Figura 8 (2016). Proyecto libre. Autorretrato (Cuarto bloque, Proyección) por un paciente de la UDC Hermanas Hospitalarias, Valencia.

Otra vez pudimos ser testigos de cómo la mayoría de las veces la importancia de la observación participativa no sólo recaía en relación con aquello que los pacientes pudieran hacer por si solos, sino también al hecho de que seguían abiertos a la incorporación de nuevos datos y acciones, seguían aprendiendo.

Bajo el título de proyección, con el fin de estimular capacidades como la atención, memoria, programación a largo plazo, flexibilidad cognitiva y conductual, marcaríamos como pauta la planificación de un proyecto creativo que cada uno debería llevar a cabo de manera individual durante cuatro sesiones continuas (planteamiento de la idea, recogida de datos- bocetos, producción trabajo final] y cerraría la programación.

\section{Resultados}

Los resultados obtenidos hasta la fecha, no sólo demuestran la posibilidad de reforzar los canales de procesamiento que implican redefinir una identidad en periodo de terapia, sino que además, alejados de utilizar las imágenes con fines diagnósticos para criticar la habilidad plástica de los 
pacientes, sí centramos la perspectiva del análisis en interpretar los mensajes que contenían. La colección de más de cien obras realizadas por nueve pacientes con DCA, permitía vislumbrar en primer plano la capacidad creativa que cada uno de ellos, desde su posicionamiento, poseía sin refreno. Demostraba la cantidad de soluciones que podían encontrar ante un mismo enunciado. Innumerables historias que no sólo eran capaces de idear con el pensamiento sino que además, la mayoría de las veces conseguían trasladar sobre el soporte justificadamente.

En pacientes con afasia o con falta de comprensión diagnosticada mencionados en los ejemplos de caso citados líneas arriba, sin ver diferencias en la seriedad con la que abordaban los talleres, sorprendentemente notamos la misma implicación y resolución de conclusiones. En las puestas en común ayudábamos en grupo a presentar e interpretar lo que sus autores en gran parte de los casos, habían querido transmitir por medio de imágenes abstractas. Conseguíamos crear un clima de complicidad y compenetración que cobijaba cada idea, interpretación o recuerdo que los participantes desearan compartir.

Bajo la calidad de estos resultados pudimos notar la implicación que contenían. La necesidad de crear excusas durante la práctica creativa para tomar y combinar nuevos vínculos que sirvieran para rellenar una parte del vacío identitario que como consecuencia del DCA había quedado.

Sin intención previa, desde nuestra área de estudio pudimos ligar, las necesidades que otras terapias realizadas paralelamente podían tener para que los pacientes desempeñaran con operatividad los tratamientos propuestos. Vimos que existía la posibilidad de combinar nuestro programa no sólo desde una práctica aislada en su contexto de rehabilitación, sino que además, según su enfoque podía aportar beneficios directos a la operatividad de programas paralelos que se llevaban a cabo.

Apoyados por cuestionarios que realizamos tanto a los participantes como al equipo de la Unidad y posteriormente cuantificamos sobre gráficas circulares, se demostró la oportunidad de explotar las posibilidades que la práctica creativa ofrece como terapia para la rehabilitación de ACV. Se abrió la posibilidad de contribuir sobre la efectividad que otros tratamientos regularizados como Neuropsicología y Terapia Ocupacional, pueden ofrecer para la recuperación de capacidades cognitivas, psicológicas y sociales de pacientes de mediana edad que hayan sufrido infartos o derrames cerebrales. Ayudar eficazmente a la mejora competitiva y máxima calidad de los servicios sociales prestados a este sector.

\section{Conclusiones}

Guiados por derechos como la inclusión, nos implicados en el esfuerzo de personas por vivir, trabajar, aprender, disfrutar y participar de forma plena en sus comunidades. Sin necesidad de 
utilizar pautas de conducta predefinidas o gustos estéticos e intelectuales de la globalización; correcto, incorrecto, común o raro, el Arte como método terapéutico y vehículo para concretizar y plasmar sentimientos, permite contribuir a la independencia mental de personas con DCA.

Sujetos a escalas de valoración, aspirando reducir las dependencias que esclavizan a este tipo de casos y ampliar nuevos canales de información, a cargo de proponer estímulos objetoemocionales lo suficientemente refinados para crear afectos que devuelvan el equilibrio y llenen cada parte, ponemos a disposición la práctica creativa como mecanismo para componer conexiones conocidas o no, que gesten sentimientos identitarios trasladables a acciones cotidianas. Demostramos la posibilidad de generar una serie de movimientos conscientes e inconscientes, que mediante claves como la motivación creen vínculos y rutas capaces de dar significado a la existencia y subrayar la importancia de su postura como individuos dentro del entorno.

La motivación y los sentimientos, como vértices de nuestro proyecto, serán considerados aspectos fundamentales para el principio de anudamiento que despiertan las respuestas y vínculos sociales creados en torno a la idea identitaria y emancipación de personas con DCA por Ictus.

\section{Referencias bibliográficas}

Augrurno. M. [2012]. Consideraciones éticas. En Atnografía y observación participante [pp.114-122].Madrid: Morata

Araujo, G. y Gabelán, G. N. [2010]. Psicomotricidad y Arteterapia. Revista electrónica interuniversitaria de Formación del profesorado, 13 [4], 307-319.

Ballesta, A. M., Onil, .V. y Mesas, C.M. [2011]. El arte como un lenguaje posible en las personas con capacidades diversas. Arte y políticas de identidad, 4, 137-152.

Bericat, E. (1998): La integración de los métodos cuantitativo y cualitativo en la investigación social. Ariel. Barcelona.

Blaxtwo , L.; Hughes, C. y Tight, M. Lecturas para la investigación. En Cómo se investiga [pp.113145].Barcelona: Grao.

Coll, F.J. [2006]. Recursos de arteterapia en el aula escolar. En P. M. Domínguez-Toscano [Coord.], Arteterapia. Nuevos caminos para la mejora personal y social [11-21]. Sevilla: Junta de Andalucía.

7 Herramientas utilizadas por el equipo de las UDC para cuantificar déficit neurológico, la gravedad y magnitud de sus secuelas 
Damasio A. [2005].En busca de Spinoza. Barcelona: Editorial Planeta S.A.

Domínguez-Toscano, P. M. [2006]. Investigación en arteterapia. En Autor [Ed.], Arteterapia: principios y ámbitos de aplicación [pp. 127-149). Sevilla: Junta de Andalucía.

Freedman. K. [2006]. Enseñar la cultura visual. Currículum, estética y la vida social del arte. Barcelona: Octaedro.

Goetz, J. P; Le Compte, M.D; [1998). Conceptualización del proceso de investigación: teoría y diseño. Etnografía y diseño cualitativo en investigación educativa. Madrid: Morata.

Hernández. M. [2016]. Manual Práctico de Salud Mental en Terapia Ocupacional. Madrid: Editorial Síntesis, S.A.

Izuel, M. y Vallès, J. [2012]. Competencias profesionales e investigación en Arteterapia. Arteterapia: Papeles de arteterapia y educación artística para la inclusión social, 7, 13-26. Recuperado de: http://dx.doi.org/10.5209/rev_ARTE.2012.v7.40758

López, M. D. [2011]. Técnicas, materiales y recursos utilizados en los procesos arteterapéuticos. Arteterapia: Papeles de arteterapia y educación artística para la inclusión social, 6, 183-191. Recuperado de: http://dx.doi.org/10.5209/rev_ARTE.2011.v6.37092-Maestre, P. J. J. [2006]. Arte, terapia y vida. En F. J. Coll [Coord.], Arteterapia: dinámicas entre creación y procesos terapéuticos [pp. 201-210]. Murcia: Servicio de Publicaciones Universidad de Murcia.

Potter, J. [1998).La representación de la realidad. Discurso, retórica y construcción social. Barcelona: Paidós.

Stake, R. E. [2005]. La naturaleza de la investigación cualitativa. En Investigación con estudio de casos(pp.40-50). Madrid: Morata.

Trías de Bes. F. [2014]. Recuperar la creatividad perdida. Ideas imprescindibles, 2, 98.

Vallés, M.S. [1997]. Técnicas cualitativas de investigación social: reflexión metodológica y práctica profesional. Madrid: Síntesis.

Wittgenstein. L. [1994]. Observaciones sobre los colores. Barcelona: Espana Libros, S. L.

U. y Universidad nacional autónoma de México, Instituto de Investigaciones Filosóficas

Plan de Atención al Ictus en la Comunidad Valenciana [2011].Valencia: Generalitat. Conselleria de Sanitat.

Federación Española de Daño Cerebral [2017]. Recuperado de: https://fedace.org 